\title{
Targeting the 'right' patients for integrated care: Stakeholder perspectives from a qualitative study
}

DOI:

$10.1177 / 1355819618788100$

\section{Document Version}

Accepted author manuscript

Link to publication record in Manchester Research Explorer

\section{Citation for published version (APA):}

Stokes, J., Riste, L., \& Cheraghi-Sohi, S. (2018). Targeting the 'right' patients for integrated care: Stakeholder perspectives from a qualitative study. Journal of Health Services Research and Policy.

https://doi.org/10.1177/1355819618788100

\section{Published in:}

Journal of Health Services Research and Policy

\section{Citing this paper}

Please note that where the full-text provided on Manchester Research Explorer is the Author Accepted Manuscript or Proof version this may differ from the final Published version. If citing, it is advised that you check and use the publisher's definitive version.

\section{General rights}

Copyright and moral rights for the publications made accessible in the Research Explorer are retained by the authors and/or other copyright owners and it is a condition of accessing publications that users recognise and abide by the legal requirements associated with these rights.

\section{Takedown policy}

If you believe that this document breaches copyright please refer to the University of Manchester's Takedown Procedures [http://man.ac.uk/04Y6Bo] or contact uml.scholarlycommunications@manchester.ac.uk providing relevant details, so we can investigate your claim.

\section{OPEN ACCESS}




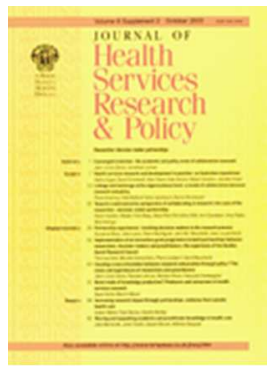

Targeting the 'right' patients for integrated care: Stakeholder perspectives from a qualitative study

\begin{tabular}{|r|l|}
\hline Journal: & Journal of Health Services Research \& Policy \\
\hline Manuscript ID & JHSRP-17-144.R1 \\
\hline Manuscript Type: & Original Research \\
\hline Keywords: & Health policy, Primary/secondary interface, Demand \\
\hline Keyword: & Integrated care, Models of care, Health systems \\
\hline \multicolumn{2}{|l}{} \\
\end{tabular}

SCHOLARONE $^{\text {Im }}$

Manuscripts 


\title{
Targeting the 'right' patients for integrated care: Stakeholder perspectives from a qualitative study
}

\author{
Jonathan Stokes \\ Research Associate, Manchester Centre for Health Economics, University of Manchester, \\ Manchester, United Kingdom. \\ Jonathan.m.stokes@manchester.ac.uk \\ Lisa Riste \\ Research Fellow, Centre for Primary Care, University of Manchester, Manchester, United Kingdom. \\ Sudeh Cheraghi-Sohi \\ Research Fellow, Centre for Primary Care, University of Manchester, Manchester, United Kingdom.
}

Corresponding author:

Jonathan Stokes

Research Associate, Manchester Centre for Health Economics, University of Manchester, Manchester, United Kingdom.

Jonathan.m.stokes@manchester.ac.uk

Keywords: Integrated care, Models of care, Health systems 


\title{
Targeting the 'right' patients for integrated care: Stakeholder perspectives from a qualitative study
}

\begin{abstract}
Objective:

To explore the perceptions of relevant stakeholders in terms of targeting the 'right' patients for integrated care.
\end{abstract}

Methods:

Secondary analysis of qualitative interviews with relevant stakeholders (including programme managers, programme initiators, a representative of the payers, medical and social care professionals, and allied health services staff) from two integrated care sites in England. A thematic analysis was conducted of cross-cutting themes.

Results:

Both sites focused on individualized management of 'high-risk' patients through multidisciplinary team case management. The data-driven approach to targeting patients, recommended in the policy literature, did not align with stakeholders' experience of selecting patients in practice. The 'right' patients were at lower risk than those 
recommended by policy, and their complexities were identified as comprising mostly social rather than medical issues.

Conclusions:

These findings raise timely questions about the individualised management approach. They potentially explain why management of high-risk patients has not been found to be effective using quantitative measures, undermining the assumption that this approach will lead to cost savings. There is a need to expand beyond an individually targeted approach to incorporate prevention and to address social issues.

\section{Introduction}

Health systems internationally face common sets of challenges, with ageing populations, increasing multimorbidity, and severe pressure on health and care budgets threatening the sustainable delivery of services. ' 'Integrated care', posited as new models of care which integrate services across different providers and sectors (for example, health and social care), is hailed as a potential solution to these challenges. ${ }^{2-4}$ In this paper, we set out the policy context for integrated care in England, the study setting. We outline the importance of potential cost savings in this setting and the policy shifts required to achieve cost savings. We use qualitative methods to explore the perceptions of relevant stakeholders in terms of 
targeting the 'right' patients for integrated care and discuss the policy implications of our findings.

\section{Background}

\section{Policy context}

The National Health Service (NHS) in England currently faces a large gap between health care funding and spending, with an estimated deficit of $£ 30$ billion a year by $2020 / 21 .^{3}$ It is argued that integrated care will simultaneously generate significant health gains alongside improvements in patient satisfaction and cost-effectiveness, a bundle of aspirations known as the 'triple aim' ${ }^{2,5}$ With its hypothetical potential for cost-saving, integrated care is envisaged as playing a key part in tackling the funding gap. Integration features heavily in the strategic vision outlined in the NHS 'Five year forward view' (FYFV) ${ }^{3}$ and the resulting exemplar new care models enacted via 'Vanguard' sites. ${ }^{6}$ It is hoped that increased costeffectiveness, by reducing overall costs, might allow funds to be reallocated to other parts of the system in most financial trouble, such as social care. Better integration, then, may not necessarily lead to overall system savings. ${ }^{7}$

In practice, the dominant application of integrated care in England (and internationally) has been via multidisciplinary team (MDT) case management. ${ }^{11}$ This involves the identification of 'high-risk' patients - those thought to be at most risk of unplanned hospital care ${ }^{8,9}$ - at the service delivery-level and provision of individually-tailored care to these patients. The evidence for the effectiveness of this approach in terms of the health system's 'triple aim', however, suggests that not all goals are positively or equally met. In particular, compared to usual care, cost is not significantly affected (that is, total cost of care, and utilization of 
secondary care services). ${ }^{10}$ Self-reported health status may be slightly improved in the short-term, but not in the long-term. ${ }^{11}$ Patient satisfaction is, however, consistently improved by case management in both the short- and long-term. ${ }^{11}$

\section{Case management and cost saving: the assumptions}

The policy context outlined above highlights the importance placed on the theoretical ability of case management to achieve reductions in costs. The process by which this aim is to be achieved rests on two assumptions.

The first assumption relates to the target group. It is well-recognized that a very small, highrisk segment of the population accounts for the majority of health care costs (that is, $5 \%$ of patients are estimated to contribute to up to $50 \%$ of spending). ${ }^{12}$ Targeting this group of 'super-utilizers' has the potential to reduce costs if their utilization of services were to decrease. ${ }^{13}$ It is worth noting, however, that in practice this is an ever-shifting group at an individual-level, with on average a regression to the mean. At least some of these high-cost individuals would return to a lower level of spending without additional long-term intervention; for example, those with a short-term acute episode of high need. Therefore, the potential savings from targeting this group are debatable. ${ }^{14}$

The second assumption relates to the mechanisms through which reduced costs may be generated. Generally, it is assumed that better clinical management and increased coordination between primary care and social care services can prevent deterioration and emergency admissions and/or can substitute for more costly secondary care services. ${ }^{13}$ This is an intuitive but largely untested assumption. Assuming care needs remain constant, any 
savings rely primarily on the difference between the large overheads in secondary care compared to primary care; for example, the costs of additional expensive medical technologies typically found in hospitals, larger premises, and twenty-four hour service delivery.

\section{Aims of this study}

As outlined, assumptions that case management will save costs do not appear to be borne out by current evidence. One potential reason that the cost-savings are not being delivered is that the wrong people are being targeted. We aimed to explore the perceptions of relevant stakeholders in terms of targeting the 'right' patients for integrated care, focusing on how patients are being targeted and why.

\section{Methods}

This paper draws on the qualitative component of the 'Sustainable intEgrated care modeLs for multi-morbidity: delivery, Financlng and pErformance' (SELFIE) project being undertaken by a partnership of European nations. ${ }^{15}$ Specifically, the paper draws on qualitative work from the two UK sites in the SELFIE project: 1) Salford (using secondary analysis of transcripts from the Comprehensive Longitudinal Assessment of Salford Integrated Care $\left[\right.$ CLASSIC] study) ${ }^{16}$ and 2) South Somerset (with interviews and transcripts conducted specifically for SELFIE). 


\section{Sampling and recruitment}

Salford and South Somerset are both 'Integrated primary and acute care system' (PACS) Vanguard sites in England. The sites were selected and funded by NHS England to join up general practice, hospital, community, and mental health services. ${ }^{6}$

The models at both sites aim to shift towards a population health management approach; that is, targeting all population 'risk' levels in some respects, not only the highest-risk. This includes a major emphasis on interventions delivered by MDT case management of high-risk patients, as outlined above, but also less targeted interventions aimed at lower-risk patients for the purpose of prevention. Both sites began their integration models with the roll-out of a range of service delivery interventions (Table 1$)$.

Table 1: Interventions in Salford and South Somerset to enhance integration, MDT case management interventions outlined in bold

[insert Table 1]

As PACS Vanguards, both sites are also looking to introduce organizational changes to help support their service delivery interventions. Both are planning to establish Accountable Care Organization (ACO)-inspired changes, with a number of providers coming together (either as a fully integrated body, or through alliances/networks) to assume responsibility for the cost and quality of care for a given population. ${ }^{17}$

In this paper, we focus on interviewee views on targeting, and on the needs of the most complex high-risk patients, that is, we focus on the MDT case management intervention in 
each site. More details of each model can be found in the thick description reports on the SELFIE website. ${ }^{18}$

Initially, the two sites set out to target slightly different 'high-risk' patient populations: Salford initially targeted those over the age of 65 (but now expanded to all adults), while South Somerset focused on those with multimorbidity (particularly, those with three or more long-term conditions). Both sites were at slightly different stages of their envisioned integrated care models at the time of this research (as shown in Figure 1 below), but both began with implementation of their MDT case management interventions.

Figure 1: Timeline of integrated care interventions in the two selected sites. Service delivery: MDG = Multidisciplinary group; $\mathrm{CoC}=$ Centre of Contact $; C A=$ Community Assets; $C C H=$ Complex Care Hub; $E P C=$ Enhanced Primary Care. Organizational: ICO = Integrated Care Organization; IP Ltd = formation of a Ltd company of Integrated GP Practices. * = Vanguard status awarded to both sites.

[insert Figure 1]

\section{Data collection}

The interviews took place at the early implementation phase at each site, with the roll-out of service delivery waves ongoing, and organizational changes still in the planning stages. Individual semi-structured interviews were conducted face-to-face with a range of professional stakeholders (including programme managers, programme initiators, a representative of the payers, medical and social care professionals, and allied health services staff) in both sites (total, $n=18$ ). 
In Salford, in order to minimize the research burden on the site and to avoid duplication of data, the transcripts were a subsample of relevant interviews conducted by researchers, including LR as part of the CLASSIC study. ${ }^{16}$ JS liaised with the CLASSIC researchers to select relevant transcripts and categorized the participants' data in order to identify which of the participants would fall within the purposive sampling frame, ensuring 'data fit' (that is, the data fit the new questions being asked) $;^{19}$ namely, those who had significant narratives around the introduction and implementation of integrated care covering an array of stakeholders. The topic guide focused on questions relating to implementation of the model. Ten stakeholder interviews meeting the SELFIE selection criteria were selected from those interviewed between November 2014 and October 2015.

South Somerset interviews were conducted (by JS) face-to-face with eight stakeholders in August 2016 and complemented the Salford interviews. The topic guide was formulated by the SELFIE work package leaders in Austria, and covered a broad range of topics around implementation and enactment of the model in practice; ${ }^{18}$ it was therefore comparable with topics covered in the Salford interviews.

All interviewees provided written informed consent and were reassured that interviews were confidential and voluntary, and data was anonymized. Ethics approval was granted by the NHS Health Research Authority Research Ethics Committee (SELFIE REF: 16/WM/0295; CLASSIC REF: 14/NW/0206). For both locations, interviews were audio-recorded and transcribed using 'intelligent verbatim' (that is, recorded speech to text, editing out pauses/repetition that distract from content) by an external agency. Recordings were rechecked for accuracy by the authors. 


\section{Data analysis}

We analysed the transcripts using thematic analysis. ${ }^{20}$ Initial familiarization with the data via reading and re-reading of transcripts was followed by initial open coding of the data which led to theme formulation as themes emerged from the data, using Microsoft Word for data management. Each site's data was independently analysed and reported separately. ${ }^{18}$ For this paper, however, we pooled the data across both sites and re-analysed the composite dataset with respect to the aims of this study. All authors discussed and reached consensus on the final analysis and presentation of the data.

\section{Results}

We identified four main themes emerging from the discussion, relating to 1 ) the motivation for case management; 2 ) the 'right' patients as a shifting target; 3 ) the actual needs of the patients; and 4 ) the possible outcomes and scope of the intervention. Below, we discuss each of these in turn and relate these perspectives to the policy context.

\section{Motivations}

Overarching motivation narratives amongst stakeholders in both sites appeared to align with the 'triple aim' of the policy. Both sites constructed a number of more specific performance measures based on these aims, using reduced emergency admissions and readmissions as a proxy for costs. Linked to this, the aim to 'stop people slipping' (who would then require high-cost and intensive hospital care) emerged as a primary motivation, with maintaining these patients' ability to self-manage a goal of both programmes. 
So the bottom of the triangle [referring to the Kaiser risk pyramid, where the top of the pyramid are a small number at highest risk, with larger numbers at the bottom at lower risk] [...] the key role there is about doing everything we can with the patients so that they're activated to manage their own health and they stay in that bottom one $[. .$.$] if they're in the middle part of the triangle then again it's about working a bit$ more intensively with them, because what you don't want them to do is to go up to the top part of the triangle. (IP02_02, South Somerset)

\title{
Shifting targets: the 'right' patients
}

\author{
Across both sites, participants described a gradual shift over time and with experience \\ gained, moving away from the policy recommendations of focusing on the highest-risk \\ patients, and towards a more flexible approach. Both shifts appear to have been bottom-up, \\ but have occurred through different methods. In Salford, this shift occurred due to \\ perceived need once the initial formal patient quotas had been filled:
}

\begin{abstract}
So the way it started out [the managers] wanted everybody with a code of three [high-risk]. I suppose part of the cynical side of me was, well, we know they're all okay because they've [already] got all the services involved but I understood that we needed to get the care plans done [...] fortunately, we got through ours fairly quickly. And it's your twos and your ones even [less high-risk], because in the blink of an eye things change, don't they? (IP09_1, Salford)
\end{abstract}


In South Somerset, this shift appeared to have been led by the experience of those professionals interacting with the patients and comparing the initial selection criteria with the reality of their 'complex patients'.

[the clinicians] were really specific about [...] three or more comorbidities, polypharmacy, high admissions. But then, again, they've had to look at, actually, you might have somebody that meets the criteria of all of those, but is managing their condition really well [...] they might have COPD [alone], and they're coming into ED every other week, because they're not managing. So we've had to just be a bit more flexible [...] So, you could have 450 patients in the service, tick a box, and say, great, but actually, they might not be the right patients, and we might still end up with the other patients being admitted, so our admission rate hasn't been impacted. (IP07_2, South Somerset)

In practice, both sites found selecting 'complex' patients from a purely formal data-driven approach difficult. Participants identified problems with risk stratification tools based on hospital data and which emphasises health care utilization. Such patients were described as well-known to health care services, frequently with little room for doing more to support reduced utilization (utilization may be necessary, so was not always seen as preventable). Additionally, other important 'unobservables' (for example, social circumstances) not present in the data were described as having more of an effect on defining patient complexity/their utilization of secondary care (see also the section on patient needs, below).

[...] what you find is the high-risk people that are identified by these risk stratification models that are promoted nationally, is that the only data that's easy to count is the hospital data [...] so the people that were at the top are the people who have most 
support from services, that because they have a lot of support from services they're usually quite well managed, and so therefore they are more reasonably stable.

(IP02_1, Salford)

Due to these insights, there has been a transition to a more fluid, active process of selection via iteration and team consensus. Stakeholders described the relative importance of getting the 'right patients' (that is, those with unmet and actionable needs), rather than simply quota filling.

Over time, it's become much more refined, really, because we've realized that some people do benefit and some people don't benefit [...] it's not a strict criteria of referral in or not referral in. It's who would best have their needs met by that service. (IP03_2, South Somerset)

So the MDGs started to work to try and find these people [...] because that is ideally what you want an MDG to do, if you see somebody slipping, that you put a little bit extra in to keep everybody afloat for $\mathrm{X}$ or $\mathrm{Y}$ amount of time longer. (IP02_1, Salford)

\section{Patient needs}

The unmet needs of complex patients were described as extending beyond the medical domain. Frequently, medical practitioners felt needs were primarily related to social factors in terms of isolation, poor housing or living arrangements, and other socio-economic issues. Clear pathways were described between these social issues and patients presenting in the 
emergency room. Linked to this, mental health needs were highlighted as being particularly challenging to address, complicated by a lack of effective treatment options.

\author{
People get very, very isolated, and when they're very isolated, they're not very \\ resilient [...] If you're happy as Larry, and you've got loads of social interaction, and \\ your family seem to care about you, and you have day-to-day contact with people, \\ you might have something wrong with you, but you deal with it... Whereas if you \\ have nobody crosses your path, and you're as miserable as sin, and it blooming \\ hurts. Well, what shall I do - I'll call the doctor, or go to A\&E. (IP05_1, Salford)
}

I think anxiety and depression are huge and I certainly didn't realize how much that impacts on a person's health and wellbeing and, you know, some people can have three, four long term conditions and can manage quite well, somebody that could have anxiety and depression could have one long term condition and it's, you know, they don't manage at all. (IP08_2, South Somerset)

Some patient needs were identified around acceptance of a chronic illness that would not alleviate, or acceptance of approaching the end of life. While some of these issues were potentially addressable, this was not the case for all.

\begin{abstract}
[...] you have other patients who are bouncing in and out of hospital. What is quite evident is actually they've got a chronic health problem that's deteriorating but nobody is really having those conversations. They are constantly feeling unwell, they are constantly feeling they need to be in hospital and of course they never get better, so they think the hospital has not done it right so they go back in and do it
\end{abstract}


again. It's [...] being able to talk through and explain that actually it's a natural progression of the condition and that's where life is now. (IP05_2, South Somerset) I've got an alcoholic bloke, who refuses to accept he's got an alcohol problem. And he must have had about 75 A\&E attendances in the last three years. And we've had multidisciplinary professional meetings [...] It's not made a jot of difference [...] he won't accept he's got problems, and he won't stop drinking. (IP05_1, Salford)

\section{Outcomes and scope}

Participants indicated that the stated aims of reducing emergency admissions and costs via case management were unlikely to be achieved, particularly in the short-term, due to the changes occurring in patient selection, as described above. Potential cost savings were seen as longer-term, where models could target lower-risk patients with preventable issues and could work to prevent future admissions. Research participants also emphasized that key intermediate steps that could lead to making savings, such as improving self-management ability, were difficult and time consuming. Additionally, there was some scepticism about the relative cost of acute episodes of hospital care versus long-term intensive community management, with some questioning whether the long-term approach would ever really save money, but recognizing it had other positive outcomes.

Cost-wise, we definitely cost money, everything we're doing is costs, you will see no savings for a long time. But quality wise, I reckon, it's through the roof. (IP04_2, South Somerset) 
However, there were also some suggestions for improving the case management intervention, in line with observed need. For example, the importance of broadening the MDT beyond a medical focus to include professionals from housing and social work was well-recognized. Social workers were included in the Salford team, and medical practitioners there described learning from them. For example, social workers provided support and advice on relocation of patients to appropriate housing to prevent falls and reduce social isolation. Particularly in Salford, where the focus was initially on older adults, the medical expertise of geriatricians were seen as particularly valuable for rationalizing care, for instance to reduce polypharmacy. Relationships developed during MDTs enabled GPs to discuss concerns about patients with geriatricians in more depth than occurred by letters alone. Likewise, mental health practitioners were highly regarded.

A number of stakeholders also highlighted the importance of a broader organizational focus on prevention, and pointed to the supporting changes planned to incentivize prevention (for example, towards establishing Accountable Care Organizations). ${ }^{21}$ They suggested that such changes would enable efficiency improvements in the wider system, which in turn would make the new models of care sustainable.

So I think the model that we're putting in will help because it's facilitating the services to work differently in specific areas. But the real efficiencies [...] so that's a different way of working, but the efficiencies have to come through the Integrated Care Organization [ACO-type organisation], I believe. (IP02_1, Salford) Importantly, despite limited impacts on costs, participants did describe some positive effects of engaging in the MDT integration approach at both sites. For example, professionals discovered additional social services offered by others within (or known to) 
the MDT that they could refer patients to. There were also examples of clear scope for improving the quality of life of patients through additional support and services. For example, alleviating loneliness through a befriending scheme for older people.

On the other hand, some stakeholders also described some concerns. One interviewee highlighted an alternative to funding case management, a wider-reaching approach provided by community services. The social engagement provided by these services was described as a particularly important preventative measure, particularly in reducing social isolation.

[...] we used to have the $[x]$ Day Centre [...] So you had frail, crumbly people, mixed in with less frail, crumbly people, who just wanted a bit of social entertainment. And that was the most amazing service, and of course, because of the cuts, it closed [...] if you want my absolute, honest opinion - I would much rather all this money that's being spent on this project, was given to social care, to start actually providing social care for patients $[. .$.$] I actually think that's what makes a difference to patients' lives.$ And I don't know whether this is going to. (IP05_1, Salford)

\section{Discussion}

\section{Principal findings}

Participants' motivations for integrating care aligned with policy in terms of achieving the overarching 'triple aim', including cost savings. However, a shift away from formal policy was evident in both sites in terms of identifying which patients to target, and the methods for doing so. This shift was a result of experience gained by local professionals. The purely 
data-driven targeting approach recommended in policy came to be seen as inadequate, as it resulted in the selection of patients already well-known to services whose needs were being met, or whose needs were unresponsive to change. Over time, the sites adopted a more fluid process of selection based on informal consensus among MDT members.

The needs of complex patients were described mostly in terms of their social situations rather than their needs for medical management. The exception was mental health conditions, where treatment options were felt to be limited. Patients' acceptance of deteriorating health was highlighted as another issue, but not always a solvable one. Suggested improvements to the case management interventions were related to these patient needs; for instance, participation of other non-medical staff.

\section{Strengths and weaknesses}

This study is based on two very different sites in England facing similar issues, which may add strength to the generalizability of the findings in terms of the commonalities they describe. However, there are limitations: data was collected from each site at different times and not for the precise purpose of answering the questions proposed here. Nevertheless, we sampled a range of stakeholders at each site, and each site was at a similar stage of implementation when interviews were conducted.

\section{Relation to other studies}

This study contributes to the published literature on targeting high-risk groups. As a qualitative article, it offers potential explanations for findings in quantitative research that case management generally fails to reduce costs. ${ }^{11}$ In the view of those implementing these interventions, achieving the goal of reduced costs is unlikely in the short-term as those at 
highest risk are not those with addressable unmet needs. Furthermore, the unmet social issues identified are often multifaceted, deeply ingrained and linked to wider social context, and therefore highly resistant to change. However, there is a clear view (from participants in this study, and findings in the wider literature) that there is the potential for quality improvement via increased personalized contact through case management interventions. Hence, we consistently see increasing patient satisfaction with this type of intervention in the literature. ${ }^{11,22,23}$

These qualitative findings complement the work of Wallace and Roland et al. ${ }^{24,25}$ who have shown, using quantitative data, the flaws in the assumption that individually targeting patients in a high-risk group will save costs: that is, studies have highlighted the extremely small number of potentially avoidable emergency admissions in this group amenable to prevention, and hence the negligible cost savings that are plausible.

\section{Implications for clinicians and policymakers}

These findings present clear implications for policymakers in terms of funding of social care and public health, both sectors where budgets have been dramatically reduced in light of austerity decisions in the United Kingdom. If the means of achieving cost savings is to be prevention of medical and social needs (and a resulting reduction of demand on services), then broader, population-wide approaches might prove a better use of resources rather than the current focus on selecting specific patients for intensive healthcare services.

Of course, not all ill-health can be prevented, and managing the highest-risk patients will remain important (aside from the economic aim of cost-saving). If such management is carried out via an MDT, our findings in relation to the needs of complex patients have 
implications for the mix of professionals who might best deliver quality care to these patients. In essence, MDTs should include those with the capability to address the multiple unmet social and/or mental health needs many patients face.

Both sites we observed have adapted their case management selection process to try and focus on impactability, that is, identifying the subgroup of patients who will tangibly benefit from the case management intervention. This may affect health inequalities. For example, focusing on those patients whose care appears suboptimal may help reduce inequalities, with suboptimal care more prevalent in deprived areas. ${ }^{26,27}$ On the other hand, excluding all of the very highest-risk patients because of a belief that they are less likely to respond to the intervention may increase health inequalities, as again, risk is associated with deprivation. ${ }^{28,}$ 29

\section{Future research}

Further research is required to determine the generalizability of this study and its findings to other models of care that emphasize integration. If case management intervention continues to be delivered to high-risk patients as a means of increasing quality of care, then studies should examine the optimal delivery methods for achieving better quality (for example, how best to select patients, MDT skill-mix, and so forth). There is also a need for increasing debate on where the limits of the responsibility lie for health systems - for example, in terms of delivering increased social support. In addition, research is required to identify where a wider governmental approach is needed in order to construct a society where an ageing population can be supported in a community where their social needs are addressed without having their problems over-medicalized. It is promising that a number of new models of care in England appear to share this long-term vision. ${ }^{6}$ 


\section{Conclusions}

These findings provide evidence about how professionals identify high-risk patients and their health and care needs, conceivably forming the basis for more effective design of future models of care for such patients. However, intensive social support delivered by a highly-paid MDT of medical and other professionals alone is unlikely to lead to cost savings in the short term. There might, however, be other valid objectives for implementing new models of care. ${ }^{30}$ Local NHS programmes currently face difficulties in moving beyond a focus on high-risk groups, despite additional start-up funding and a national vision to do so. With increasing financial pressure, more work is also needed to design and deliver cost-effective models of care across an ageing and increasingly multimorbid population.

\section{References}

[1] Nolte E amd McKee M. Caring for people with chronic conditions: A health system perspective. McGraw-Hill International, 2008. [cited 04/06/2018]; Available from: http://www.euro.who.int/ data/assets/pdf file/0006/96468/E91878.pdf [2] World Health Organization. WHO global strategy on people-centred and integrated health services: Interim report, 2015. [cited 04/06/2018]; Available from: http://www.who.int/servicedeliverysafety/areas/people-centred-care/global-strategy/en/ [3] NHS England. Five year forward view, 2014: 1-41 [cited 04/06/2018]; Available from: https://www.england.nhs.uk/wp-content/uploads/2014/10/5yfv-web.pdf

[4] Goodwin N, Smith J, Davies A et al. Integrated care for patients and populations: Improving outcomes by working together. London, UK: The King's Fund, 2012. [cited 04/06/2018]; Available from: https://www.kingsfund.org.uk/sites/default/files/integratedcare-patients-populations-paper-nuffield-trust-kings-fund-january-2012.pdf [5] Department of Health. Integrated care and support: Our shared commitment. London, UK: Department of Health, 2013: 1-46 [cited 04/06/2018]; Available from: https://www.gov.uk/government/publications/integrated-care

[6] NHS England. New care models - vanguard sites, 2016. [cited 04/06/2018]; Available from: https://www.england.nhs.uk/new-care-models/vanguards/

[7] NHS England. Better care fund, 2016. [cited 04/06/2018]; Available from: https://www.england.nhs.uk/ourwork/part-rel/transformation-fund/bcf-plan/

[8] Stokes J, Checkland K and Kristensen SR. Integrated care: Theory to practice. $J$ Health Serv Res Policy 2016; 21: 282-5 
[9] Erens B, Wistow G, Mounier-Jack S, et al. Early evaluation of the integrated care and support pioneers programme. London, UK: Policy Innovation Research Unit, 2015. [cited 04/06/2018]; Available from:

http://www.piru.ac.uk/assets/files/Early evaluation of IC Pioneers Final Report.pdf [10] Huntley AL, Thomas R, Mann M, et al. Is case management effective in reducing the risk of unplanned hospital admissions for older people? A systematic review and metaanalysis. Family Practice 2013; 30: 266-75

[11] Stokes J, Panagioti M, Alam R, et al. Effectiveness of case management for 'at risk' patients in primary care: A systematic review and meta-analysis. PLOS ONE 2015; 10: $\mathrm{e} 0132340$

[12] Government Accountability Office. Medicaid: A small share of enrollees consistently accounted for a large share of expenditures. United States Government Accountability Office, 2015: 1-45 [cited 04/06/2018]; Available from:

https://www.gao.gov/assets/680/670112.pdf

[13] Monitor. Closing the NHS funding gap: How to get better value health care for patients. 2013: 1-23 [cited 04/06/2018]; Available from:

https://www.gov.uk/government/publications/closing-the-nhs-funding-gap-how-to-get-bettervalue-healthcare-for-patients

[14] Johnson TL, Rinehart DJ, Durfee J et al. For many patients who use large amounts of health care services, the need is intense yet temporary. Health Affairs 2015; 34: 1312-9 [15] Struckmann V, Spranger A, van Ginneken E, et al. Executive summary of work package 1: Conceptual framework to review integrated chronic care (ICC) models for multimorbidity and select the most promising programmes. 2016: 1-18 [cited 04/06/2018];

Available from: https://www.selfie2020.eu/wpcontent/uploads/2016/08/20160729 SELFIE final_version_Executive_Summary WP1.pdf [16] Bower P, Camacho C, Campbell S, et al. Protocol for the classic. Comprehensive longitudinal assessment of salford integrated care (classic): A study of the implementation and effectiveness of a new model of care for long-term conditions. 2014 [cited 01/06/2017]; Available from: https://njl-admin.nihr.ac.uk/document/download/2007705

[17] Shortell S, Addicott R, Walsh N, et al. Accountable care organisations in the United States and England. Testing, evaluating and learning what works London: The Kings Fund. 2014 [cited 04/06/2018]; Available from:

https://www.kingsfund.org.uk/sites/default/files/field/field_publication_file/accountable-careorganisations-united-states-england-shortell-mar14.pdf

[18] Stokes J, Cheraghi-Sohi S, Kristensen SR, et al. Selfie work package 2 report: United Kingdom. 2016 [cited 08/02/2017]; Available from: http://www.selfie2020.eu/wpcontent/uploads/2016/12/SELFIE WP2 UK Final-thick-descriptions.pdf [19] Heaton J. Secondary analysis of qualitative data: An overview. Historical Social Research / Historische Sozialforschung 2008; 33:33-45

[20] Braun V and Clarke V. Using thematic analysis in psychology. Qualitative Research in Psychology 2006; 3: 77-101

[21] Ham C. Making sense of integrated care systems, integrated care partnerships and accountable care organisations in the NHS in England. 2018 [cited 06/04/2018]; Available from: https://www.kingsfund.org.uk/publications/making-sense-integrated-care-systems [22] Gowing A, Dickinson C, Gorman T, et al. Patients' experiences of a multidisciplinary team-led community case management programme: A qualitative study. BMJ Open 2016; 6 [23] Sheaff R, Boaden R, Sargent P, et al. Impacts of case management for frail elderly people: A qualitative study. J Health Serv Res Policy 2009; 14: 88-95 
[24] Wallace E, Smith SM, Fahey T, et al. Reducing emergency admissions through community based interventions. BMJ 2016; 352

[25] Roland $\mathrm{M}$ and Abel G. Reducing emergency admissions: Are we on the right track? BMJ 2012; 345

[26] Hart JT. The inverse care law. The Lancet 1971; 297: 405-12

[27] Mercer SW, Zhou Y, Humphris GM, et al. Multimorbidity and socioeconomic deprivation in primary care consultations. The Annals of Family Medicine 2018; 16: 127-31 [28] Lewis G. Next steps for risk stratification in the NHS. London: NHS England 2015 [cited 08/01/2018]; Available from: https://www.england.nhs.uk/wpcontent/uploads/2015/01/nxt-steps-risk-strat-glewis.pdf [29] Lewis GH. "Impactibility models": Identifying the subgroup of high-risk patients most amenable to hospital-avoidance programs. The Milbank Quarterly 2010; 88: 240-55

[30] Stokes J, Man M-S, Guthrie B, et al. The foundations framework for developing and reporting new models of care for multimorbidity. The Annals of Family Medicine. 2017; 15: $570-7$ 


\section{Acknowledgements}

The authors would like to thank the CLASSIC researchers who allowed us to analyse a proportion of their transcripts for the SELFIE project, and all those stakeholders across the two programmes who took the time to be interviewed. We would like to thank 'Salford Together' - a partnership of Salford City Council, NHS Salford Clinical Commissioning Group, Salford Royal NHS Foundation Trust, Greater Manchester Mental Health NHS Foundation Trust and Salford Primary Care Together. We would like to acknowledge all members of the SELFIE consortium for their support in the development of the project and contributions to this publication.

\section{Funding}

This SELFIE project has received funding from the European Union's Horizon 2020 research and innovation programme under grant agreement No 634288. The content of this work reflects only the SELFIE groups' views and the European Commission is not liable for any use that may be made of the information contained herein. The CLASSIC project was funded by the National Institute for Health Research Health Services and Delivery Research $(12 / 130 / 33)$. The views and opinions expressed therein are those of the authors and do not necessarily reflect those of the HS\&DR, NIHR, NHS or the Department of Health. 


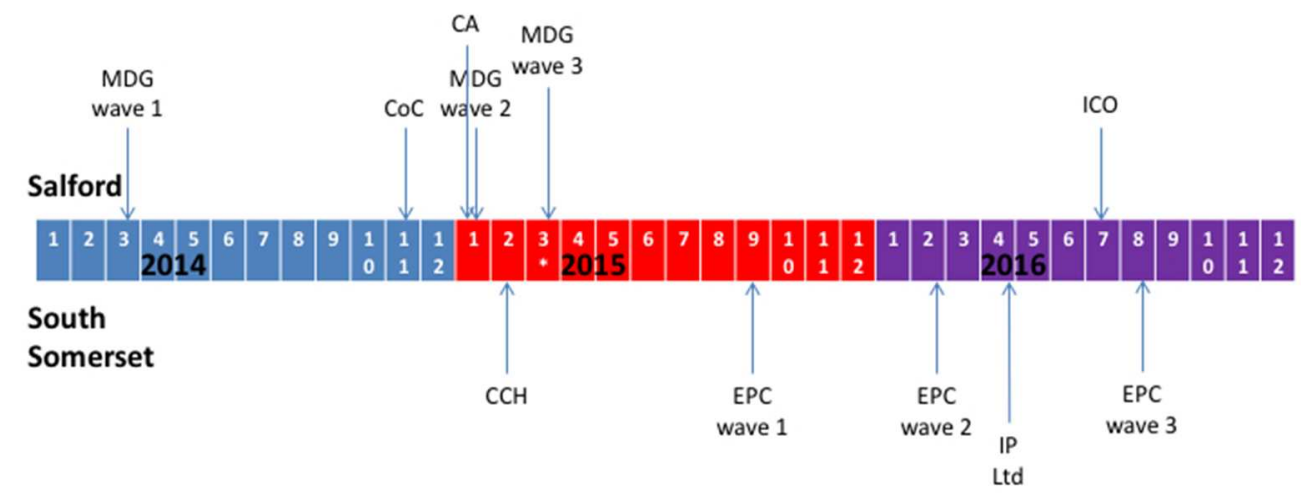

Figure 1: Timeline of integrated care interventions in the two selected sites. Service delivery: MDG = Multidisciplinary group; $\mathrm{CoC}=$ Centre of Contact; $\mathrm{CA}=$ Community Assets; $\mathrm{CCH}=$ Complex Care Hub; $\mathrm{EPC}=$ Enhanced Primary Care. Organisational: ICO = Integrated Care Organisation; IP Ltd = formation of a Ltd company of Integrated GP Practices. * = Vanguard status awarded to both sites. 
Salford

- MDT case management of the

highest-risk patients by

neighbourhood groups

- Centre of contact - a centralised

telephone hub to help with

navigating services and self-

management (via health coaching)

- Community assets - investment in

community resources to promote

social interaction and active lifestyles

later in life
South Somerset

- Complex care hubs - an 'extensivist' GP intervention with GPs located in a hospital hub case managing the most complex patients in MDTs

- Enhanced primary care - co-location of health coaches in GP practices to assist with disease self-management and prevention 